41 (3) | 2012

Recomposiciones territoriales de las periferias de las metrópolis andinas

\title{
La forma urbana de Quito: una historia de centros y periferias
}

La forme urbaine de Quito : une histoire de centres et de périphéries

Quito's urban form: a history of centers and peripheries

Fernando Carrión y Jaime Erazo Espinosa

\section{OpenEdition}

Journals

Edición electrónica

URL: http://journals.openedition.org/bifea/361

DOI: 10.4000/bifea.361

ISSN: 2076-5827

Editor

Institut Français d'Études Andines

Edición impresa

Fecha de publicación: 31 diciembre 2012

Paginación: 503-522

ISSN: 0303-7495

Referencia electrónica

Fernando Carrión y Jaime Erazo Espinosa, « La forma urbana de Quito: una historia de centros y

periferias », Bulletin de l'Institut français d'études andines [En línea], 41 (3) | 2012, Publicado el 01 agosto 2013, consultado el 05 noviembre 2020. URL : http://journals.openedition.org/bifea/361 ; DOl : https:// doi.org/10.4000/bifea.361

\section{c) $(7) \Theta$}

Les contenus du Bulletin de l'Institut français d'études andines sont mis à disposition selon les termes de la licence Creative Commons Attribution - Pas d'Utilisation Commerciale - Pas de Modification 4.0 International. 


\title{
La forma urbana de Quito: una historia de centros y periferias*
}

\author{
Fernando Carrión ${ }^{* *}$ \\ Jaime Erazo Espinosa*** (con la colaboración de)
}

\begin{abstract}
Resumen
El presente artículo busca aportar elementos analíticos para reconstruir los procesos sociales reales sobre los cuales se cimentan la lógica y las transformaciones del contexto urbano de Quito. Para el efecto se presentarán, bajo una estructura expositiva, las transformaciones históricas de la cuestión urbana en Quito. Asimismo, se caracterizarán los dos períodos principales del desarrollo urbano de la ciudad, el de consolidación del Estado nacional y el de modernización capitalista, ambos en base a sus rasgos más sobresalientes, teniendo como directrices las definiciones de crisis-transición urbana, de forma y organización territorial, de políticas urbanas, de los sectores sociales, entre otros aspectos.
\end{abstract}

Palabras clave: Quito, organización territorial, crisis urbana, política urbana, desarrollo urbano, Municipio de Quito

* Este artículo es resultado de un proceso de investigación continúa que empezó en el año 2000. Varias temáticas le han dado contenido, desde los estudios sobre la centralidad fundacional hasta la ubicación geográfica de la violencia urbana y la inseguridad. Así, los momentos históricos cruciales de la forma de organización territorial en Quito son las búsquedas del proceso investigativo.

** Presidente de la Organización Latinoamericana y del Caribe de Centros Históricos (Olacchi) y Editorialista de Diario Hoy. Quito, La Pradera E7-174 y Diego de Almagro. E-mail: fcarrion@flacso. org.ec

*** Coordinador del Programa Académico en Desarrollo Urbano del Instituto de Altos Estudios Nacionales (IAEN), Profesor en Flacso sede Ecuador y en la Universidad Central del Ecuador, y coCoordinador del Grupo de Trabajo Hábitat Popular e Inclusión Social del Clacso. Quito, Amazonas N37-271 y Villalengua. E-mail: Jaime.erazo@iaen.edu.ec 


\title{
La forme urbaine de Quito: une histoire de centres et de périphéries
}

\section{Résumé}

Cet article cherche à fournir des éléments d'analyse pour reconstruire les processus sociaux réels sur lesquels reposent la logique et les transformations du contexte urbain de Quito. Nous allons donc présenter, sous forme d'exposition, les transformations historiques des problèmes urbains de Quito. Nous présenterons également les deux grandes périodes de développement urbain de la ville, la consolidation de l'État et la modernisation capitaliste, à partir de leurs caractéristiques les plus saillantes en prenant, entre autres, comme lignes directrices, les définitions de la crise urbaine de transition, la forme et l'organisation des politiques territoriales et urbaines et le secteur social.

Mots clés : Quito, l'organisation territoriale, la crise urbaine, la politique urbaine, le développement urbain, la municipalité de Quito

\section{Quito's urban form: a history of centers and peripheries}

\begin{abstract}
This article will provide analytical elements to reconstruct the actual social processes upon whose foundations the logic and transformations of the urban context of Quito have been built. To do this, using an expository structure, the historical transformation of urban issues in Quito will be presented. Similarly, the two main periods of urban development in the city will be characterized, as will the consolidation of the national state and the consolidation of the capitalist modernization, both based on the most salient features, taking as guidelines the definitions of urban crisis transition, the shape and territorial organization of territorial and urban policies, and of social sectors, among other factors.
\end{abstract}

Key words: Quito, territorial organization, urban crisis, urban policy, urban development, the Municipality of Quito

El proceso urbano de Quito tuvo durante el último siglo dos momentos históricos cruciales: el primero, definido por el predominio de las relaciones capitalistas de producción, la constitución del Estado nacional y la articulación bicefálica de la urbanización en el país, que corresponden, cronológicamente, al período de la Revolución Liberal (1895-1910); y el segundo, caracterizado por un agudo proceso de transformaciones tan solo comparable en magnitud e importancia con el momento anterior, deducido del proceso de modernización capitalista que vivió(e) el Estado y la sociedad civil en el conjunto del país (1960-1980).

Cada uno de estos hitos tuvo su expresión en la ciudad a través de lo que hemos llegado a conceptualizar como «crisis urbana»1, teniendo cada uno de ellos mayor

1 En 1979, Fernando Carrión definió a «crisis urbana» como «(...) la exacerbación de la contradicción entre las relaciones de producción y la socialización de las fuerzas productivas, que se expresa al momento en que la organización territorial en todas sus manifestaciones, no pueda cumplir con la amplia gama de requerimientos impuestos por la evolución del resto de la sociedad (...)». 
o menor intensidad según las circunstancias particulares de las cuales han sido parte constitutiva. Esto es, en relación a los cambios que se operan a nivel de la lógica de acumulación/dominación, el rol que Quito cumple en el proceso de urbanización y las características que asume la organización territorial intraurbana en la ciudad.

\section{LA CRISIS URBANA CON LA CONSOLIDACIÓN DEL ESTADO NACIONAL (1895-1910)}

Con el desarrollo de las fuerzas productivas gestadas desde el siglo XVIII, se comenzó a sentar las bases para el ulterior proceso de acumulación originaria, así como del proceso de urbanización en el paísz, teniendo en los dos casos a la Revolución Liberal como su punto culminante. Sin embargo, uno y otro proceso no pueden entenderse bajo una relación mecánica, ni tampoco puede concebirse sus expresiones en el tiempo y en el territorio, de forma homogénea.

Aún más, la desintegración de las formas precapitalistas de producción que precedieron a la dominación de la sociedad burguesa en el Ecuador, condujo a la agudización de las desigualdades y disparidades regionales previamente existentes3. Tal situación no es otra cosa que el resultado de la integración, primero, y la articulación después de dos regiones distintas (sierra-costa), a través de sus centros urbano-regionales principales (Distrito Metropolitano de Quito y Guayaquil). Con eso se modifica la relación histórica campo-ciudad, se consolida el modelo de agro-exportación y se define la forma bicefálica del proceso de urbanización ecuatoriano. De esta manera, en el país se configuró una organización territorial sobre la base de la relación entre la plantación costeña — dirigida su producción al mercado internacional para atraer divisas-, y la hacienda serrana —que lo hace para el mercado interno de base urbana-.

Con el establecimiento de la bicefalia urbana Quito-Guayaquil, se tendió, en consecuencia, a modificar el rol y las funciones de Quito en el contexto nacional; dado que al asumir la condición de centro regional principal de la sierra (hacienda)

2 Entenderemos por proceso de urbanización a los fenómenos capitalistas de distribución territorial de la población y de organización territorial (como superposición y articulación de distintas formas productivas que conforman ámbitos de relaciones particulares y regionalizados objetivamente), íntimamente articulados y deducidos de sus determinaciones principales, tales como las transformaciones en las relaciones de intercambio, distribución y consumo, en la estructura de clases, en el Estado, en la relación del campo y la ciudad, etc. (Carrión, 1984).

3 «La original división político-administrativa de la República, expresa visiblemente el carácter descentralizado a que hacemos referencia. El territorio está dividido en tres departamentos que tienen en su interior a las provincias, cantones y parroquias. Cada una de estas entidades tiene instancias de control y decisión autónomas o semiautónomas con amplia cuota de poder, pero el ejecutivo central conserva casi exclusivamente la dirección de las relaciones exteriores y el control de algunas contribuciones. Los municipios, juntas de hacienda, cuerpos gubernativos de instituciones locales, dirigidos por los notables, tienen en algunos casos, mayor capacidad económica y política que el propio gabinete presidencial» (Ayala, 1982: 53). 
asociado al de la costa (plantación), formó con Guayaquil un eje de procesos de urbanización y acumulación a escala nacional.

De igual manera, se percibieron cambios sustanciales en el conjunto de la sociedad nacional, y de Quito en particular, en lo que se refiere a aspectos como por ejemplo, el nacimiento, aunque incipiente, de la industria; el dominio del capital comercial; la formación del capital bancario; la «urbanización» de ciertos sectores de terratenientes, etc.

Como consecuencia del proceso de desarrollo capitalista al que se asistió en aquel período, la organización urbano-territorial de la ciudad comenzó a mostrar niveles de «desajuste». Una de las primeras evidencias tuvo que ver con la saturación, compactación y consolidación, al extremo, de la mancha urbana de la ciudad: para aquel entonces (1904), la ciudad alcanzó su más alta densidad histórica (276 habitantes/hectárea).

Así mismo, se reveló el agotamiento, por un lado, de la forma de organización territorial imperante, y por otro lado, de los instrumentos y mecanismos específicos que la configuraron; esto fue, la segregación residencial como elemento dominante de la división social del espacio en aquel período. Es decir que caducaron los mecanismos pre-capitalistas de apropiación-habilitación-utilización del suelo urbano de calidad, altamente condicionados por el despojo y el reparto heredados de una jerarquía social colonial, con fuerte incidencia de la Iglesia Católica.

En suma, los pasados fenómenos de transformación urbano-territorial nos mostraron el agotamiento de la forma de organización de tipo radial concéntrica, hasta aquel momento imperante, y evidenció, como consecuencia, el nivel más alto al que ha llegado la crisis urbana (fig. 1).

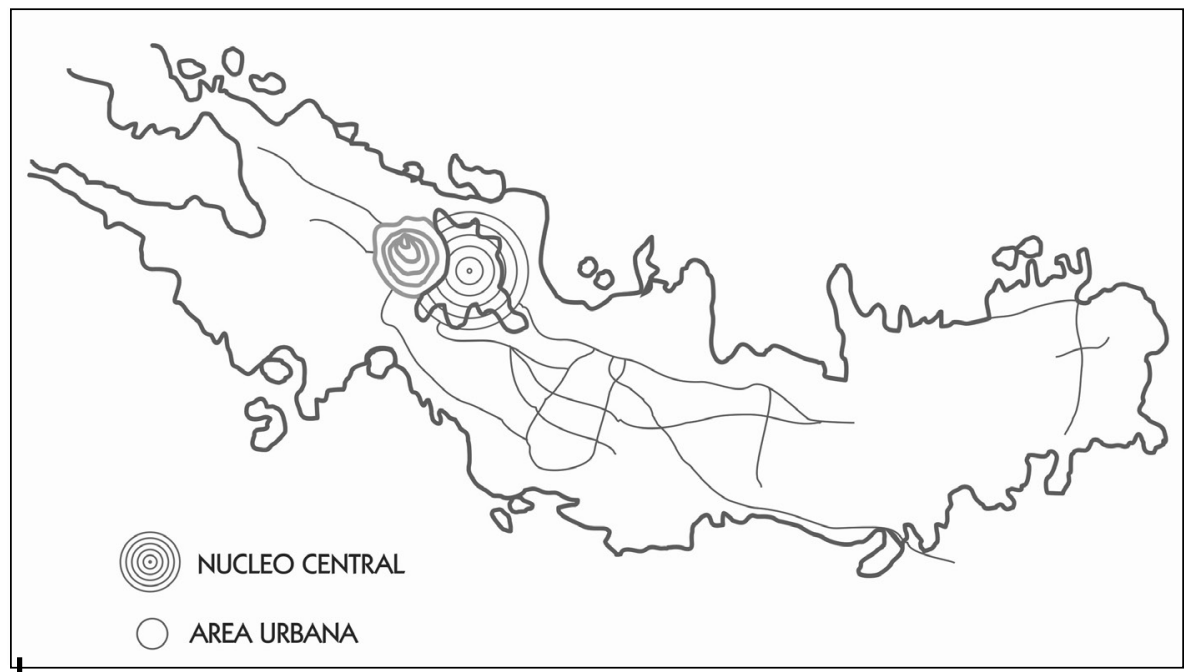

Figura 1 - Esquema de la forma de organización territorial radial concéntrica (1748-1904)

Elaboración propia 
Los cambios que ocurrieron al interior de la ciudad no se hicieron esperar y en un lapso de pocos años se modificó sustancialmente la organización urbanoterritorial y las bases sobre las cuales descansaba. Quito empezó, a partir de entonces, a sufrir transformaciones urbanas 4 , las cuales tendieron a solventar la primera crisis urbana de tipo capitalista. Esto fue, en última instancia, el resultado de la contradicción que se desarrolló entre las relaciones de producción y la socialización de las fuerzas productivas.

Así los cambios comenzaron a surtir efecto en la organización urbano-territorial de la ciudad, entre otras cosas con la llegada del ferrocarril por el extremo sur, con la incorporación de los servicios públicos fundamentales (agua potable, energía eléctrica, alcantarillado), con el desarrollo del equipamiento colectivo (parques, colegios, centros de salud), con la construcción de nuevas edificaciones, y con la formación de barrios con características inéditas que dieron un nuevo carácter a la ciudad.

La superación de la crisis se dirigió hacia un proceso paulatino de fortalecimiento capitalista de la ciudad. Así, entre los principales elementos para remontar la crisis, se presentaron: a) la emergencia de un proceso de valorización del suelo urbano que se tradujo en su masiva mercantilizacións; b) el desarrollo de una nueva forma de organización urbano-territorial de tipo longitudinal primero y longitudinal-polinuclear después (fig. 2); c) la constitución de una nueva fracción de la clase terrateniente con base urbana, y finalmente, d) la adopción de un nuevo contenido por parte de la política urbana municipal.

Si bien este período de transición urbana fue concebido como una unidad que abarcó cerca de cuarenta años (1910-1950), ello no significó que, por un lado, sea absolutamente homogéneo a lo largo del tiempo ni, por otro lado, se lo entienda linealmente. De allí que el período de transición comprendió en su interior una fase de superación de la crisis, y en otra, de consolidación del modelo de transición, en el cual se presentaron los orígenes de una nueva crisis.

La forma de organización urbana-territorial que emergió de la crisis urbana se constituyó por una segregación residencial especificada longitudinalmente de norte a sur, en zonas homogéneas al interior y heterogéneas entre ellas; así tuvimos: al norte los sectores de altos ingresos, al centro los tugurizados y al sur los de bajos ingresos. El acelerado y desigual proceso de constitución y habilitación del suelo urbano, logró en 18 años (1904-1922) cuadruplicar el área de la ciudad e impulsó la especulación con la tierra urbana.

Tal forma de organización no fue otra cosa que el resultado de la profundización de los mecanismos capitalistas de habilitación, circulación y utilización del

4 «Se dice que Quito tuvo 28000 habitantes en 1780; alrededor de 35000 cuando se independiza. Si esto es así, en 1905 apenas había recuperado el tamaño que tuvo siglos antes» (Salgado, 1978: 22).

5 La valorización del suelo urbano se produjo cuando la producción capitalista de los edificios suplantó a la producción no mercantilista, es decir el momento en que el suelo urbano comenzó a ser soporte de actividades económicas en las que su fin fue la valorización de los capitales. 


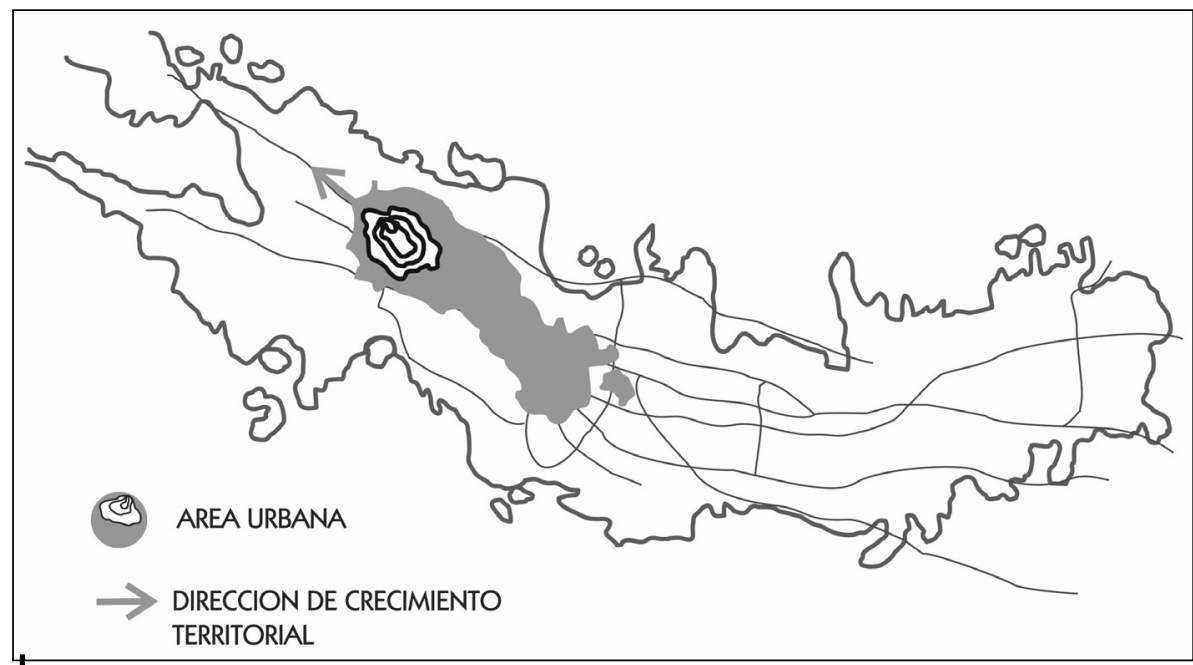

Figura 2 - Esquema de la forma de organización territorial longitudinal (1904-1960)

Elaboración propia

suelo urbano, con la consecuente modificación de los factores geográficos que condicionaron la implantación de la ciudad. Esta situación fue dable en la medida en que se generalizó el proceso de valorización capitalista de la tierra urbana, y en ello confluyeron históricamente los siguientes factores principales:

- Dominó el modo de producción capitalista y se consolidaron el Estado nacional, la integración regional y la ciudad de Quito como capital de la República.

- Se desarrolló, de manera paulatina, el proceso de industrialización y también su correlato, la producción de base urbana y concentrada en Quito y Guayaquil.

- Se desarrollaron las condiciones propicias para la producción capitalista inmobiliaria, con las siguientes consecuencias:

$\checkmark$ El crecimiento y la integración del mercado inmobiliario sobre la base de la acumulación de las rentas territoriales (agrícolas y urbanas),

$\checkmark$ La reducción del obstáculo relativo que significó la tierra para la producción,

$\checkmark$ El incremento de una demanda estratificada.

Por ello se iniciaron, por un lado, procesos de acumulación de capital en el sector inmobiliario y, por otro lado, procesos de intensificación de uso de suelo urbano en la zona central (tugurización), así como el fraccionamiento, urbanización y poblamiento de áreas periféricas localizadas principalmente hacia el norte de la ciudad (expansión).

- Se formó una demanda de edificación estratificada, según los ingresos y la oferta limitada. Esto condujo al desarrollo de la renta de monopolio (por las características del mercado), y se convirtió en el componente principal de la renta urbana. Sin duda alguna, elementos importantes en la creación de la demanda estratificada fueron: la inmigración campesina que se desató en la 
primera década del siglo XIX y la pauperización creciente de las masas urbanas. Estos elementos se dieron en la medida en que permitieron conformar al «sujeto social» capaz de pagar, a través del alquiler, las rentas urbano-territoriales (de monopolio y diferencial) de la zona central de la ciudad, e iniciaron de esa manera, la lógica económica de la tugurización6. Se posibilitó entonces, la primera gran movilidad residencial de los sectores de altos ingresos del Centro Histórico de Quito a la Mariscal Sucre. Con aquella expansión urbana, se produjo la atomización de la propiedad tanto en el centro de la ciudad (tugurización) como en la periferia, y la continua revalorización de la tierra urbana7.

Puede señalarse, entonces, que la valorización del suelo urbano resultó y condujo a, por un lado, la redefinición de la forma de organización urbanoterritorial y, por otro lado, al aparecimiento de una nueva fracción terrateniente en el país: la urbana. Su origen pudo encontrarse en la confluencia de tres vertientes complementarias:

$\checkmark$ la conversión de la renta agrícola en capital, al transferirse del sector agrario al inmobiliario como inversión;

$\checkmark$ la transformación de los terrenos agrícolas periféricos de la ciudad en terrenos urbanos sujetos a la especulación;

$\checkmark$ la acumulación de las rentas monopólicas y diferenciales obtenidas en el centro de la ciudad, bajo la forma de alquiler (tugurio) o de venta de los inmuebles, e invertidas como capitales en el sector inmobiliario.

Esta situación evidenció en la práctica la estrategia terrateniente de, por un lado, valorizar la tierra del conjunto de la ciudad y, por otro lado, transferir por este mecanismo parte de la crisis económica de los años 1920 y 1930 hacia los sectores populares, ubicados principalmente, como ya antes se dijo, en el centro de la ciudad. La modalidad no será otra que la apropiación de la renta del suelo, a través del alquiler. Ello explica la lucha llevada a cabo por los arrendatarios que condujo a la constitución de una «Liga de inquilinos» en 1930, con el fin de velar por los intereses de las personas de escasos recursos económicos principalmente, y que por tales circunstancias se ven precisados a vivir arrendando moradas.

La propiedad del suelo agrario y/o urbano (en la mayoría de los casos la propiedad urbana se evidencia como una extensión de la rural), se convirtió en la fuente originaria de la valorización de la tierra urbana (renta absoluta) y, por lo tanto, nació el terrateniente urbano, el capital rentista.

Evidentemente tal transformación de la escena urbana se produjo como resultado de, y concomitantemente a, las transformaciones históricas del momento particular que se vivía en el país, y tuvieron mucho que ver con el proceso de separación de

6 La lógica económica subyacente a la tugurización puede ser caracterizada según el refrán popular de que «muchos pocos hacen mucho».

7 Es importante remarcar la diferencia jugada por la propiedad de la tierra en cada una de las crisis: si en la primera se pretendió la atomización como forma de monetarización con las rentas territoriales, en la segunda el proceso fue inverso: concentró la propiedad para reiniciar nuevos ciclos productivos. En la primera es una estrategia terrateniente, en la segunda del capital de promoción. 
la sociedad civil y el Estado (gestado décadas atrás). Ello condujo inevitablemente a un tipo de dominación indirecta de la clase hegemónica (burguesía comercial principalmente) sobre las subordinadas, teniendo como base de existencia, otros elementos, de «órganos estatales de intermediación», como el poder concentrado en la clase dominante (poder central) y el poder difuso de ciertos «intereses particulares» definidos en ámbitos específicos de relaciones (poder del gobierno local).

El nuevo Municipio que emergió de la coyuntura (1945) constituyó este «órgano estatal difuso y de intermediación». Como bien lo señala Castells, el Municipio es «el nivel más descentralizado del Estado, el más penetrado por la sociedad civil, el más accesible a los gobernados, el más directamente ligado a la vida cotidiana. Las relaciones Estado central-Municipio son el indicador más claro de las relaciones generales entre el Estado y la sociedad civil» (Castells, 1981: 300).

En ese sentido, el proceso de dominación del capital en el conjunto de la formación económica y social ecuatoriana y el correlativo desarrollo de la estructura del Estado significaron, en la práctica, un desplazamiento relativo de ciertos sectores terratenientes del poder global nacional hacia otros ámbitos más reducidos de poder político. Desplazamiento relativo, en tanto que el Estado centralizado - característico de la sociedad moderna- descansaba sobre bases latifundistas en las que el centralismo burgués coexistió con el gamonalismo o caciquismo local. Desplazamiento relativo también, por cuanto el desplazamiento de los terratenientes del poder nacional hacia el poder municipal posibilitó el remozamiento de la clase terrateniente a través del nacimiento de su fracción urbana y, consecuentemente, de su inserción en la economía de la ciudad.

Es importante señalar que este remozamiento de la clase terrateniente tuvo lugar en el ámbito privilegiado del dominio latifundista: el Municipio como poder local. Resaltando la afirmación, se puede señalar que, si en la Conquista y colonización, el Municipio fue el punto de partida para que los vecinos de la ciudad (propietarios de tierras con título) logren dominar y consolidar la producción agrario-minera circundante, entonces a partir de esta coyuntura histórica será un instrumento del terrateniente agrario para «modernizarse» o remozarse en tanto terrateniente urbano, y consolidarse posteriormente como fracción. De allí se infiere, entonces que, dependiendo del momento histórico que sea, el Municipio adquirirá un poder más o menos limitado, pero real.

En ese contexto histórico, el contenido del poder del Municipio se limitó hacia lo que podríamos considerar como «lo urbano». Al producirse la diferenciación de las competencias entre el poder central y el local, se circunscribieron el ámbito y sustento principal del poder del Municipio a una porción del territorio cantonal: la ciudad de Quito. De igual manera, se limitaron a un segmento del ejercicio del poder: la política urbana. Es a partir de este período que la política urbana del Municipio privilegió las acciones relativas al papel que se le asignó a la tierra.

La política urbana del Municipio de Quito durante el período de transición urbana, mostró dos momentos importantes que merecen ser resaltados: el primero, correspondió a la «urbanización» de los terratenientes agrarios (1904-1922), y el segundo, al proceso de consolidación de la fracción urbana de aquellos (19221955). El motor del primer momento lo constituiría: 
La acción particular iniciada interesadamente y en exclusivo beneficio propio, por los dueños de terrenos que antes de hoy fueron huertas, potreros o eucaliptos, en las afueras del núcleo urbano. Medían el terreno, señalaban en un croquis o plano las futuras calles y un número de lotes que rindieran ganancias apreciables y los ofrecían en venta al público necesitado a precios al parecer ventajosos. Para facilitar la venta comenzaron a dar facilidades de pago, aceptando abonos mensuales o trimestrales desde luego, dejando al Municipio los costosos trabajos de urbanización (Paz y Miño, 1960: 30).

Algunos hechos de la cita merecen ser comentados: primero, la gran articulación existente entre los terratenientes agrarios («dueños de eucaliptos, potreros, huertas en las afueras del núcleo urbano») y el Municipio, para convertirse en urbanos («dejando al Municipio los costos de urbanización»); segundo, el mecanismo de conversión de la tierra agraria a urbana, mediante el proceso de valorización de la tierra descrito anteriormente. Esto es, el proceso de habilitación y valorización del suelo urbano emprendido por el Municipio cuando construye obras de urbanización en terrenos privados. En este caso, el proceso de habilitación genera la valorización del suelo urbano junto con la producción de las obras de urbanización emprendida por el Municipio -a pérdida económica, pero son los terratenientes quienes se apropian de la renta (diferencial principalmente) generada - Es por ello que esta apropiación de la renta debe ser entendida como una transferencia de una parte de la plusvalía social captada por el Municipio vía tributación, hacia los terratenientes como renta o sobreganancia de localización. De esta manera y muy sucintamente esbozado, el carácter de la política urbana del Municipio de Quito en este período se convirtió finalmente en el instrumento de prolongación del terrateniente agrario a urbano; en el sustento del capital para la formación de las condiciones generales de la producción; en el promotor del proceso de acumulación en la rama de la construcción; y todo ello condujo a la progresiva pérdida de su capacidad de respuesta económica frente a las necesidades crecientes, cuestión que definitivamente cobró mayor peso con la crisis de las exportaciones y la depresión mundial de 1929.

Esta política tendió a reajustarse en función de las limitaciones internas y de los efectos inmediatos que provocó la coyuntura internacional. Así, se puede considerar que 1933 constituye el punto de inflexión, cuando el Municipio dictó una ordenanza que estableció, como requisitos previos a la venta de solares, la obligatoriedad para el propietario de realizar obras de urbanización y de solicitar la aprobación del fraccionamiento con el Departamento de Obras Públicas Municipales.

Con esta evidencia, el Municipio experimentó una nueva modalidad de intervención que estuvo en consonancia con el momento histórico señalado, con las necesidades concretas de los terratenientes urbanos en camino a consolidarse, y con el nacimiento del capital comprometido en el sector de la construcción8. Tal situación

8 En la edición de la revista Cegan (1951), en su sección de promoción comercial, se menciona que las cuatro empresas constructoras que anuncian sus servicios fueron fundadas en un período de dos 
solo fue posible gracias a una política estructurada para apoyar esos sectores bajo la modalidad de una política urbana cuya lógica condujo a la exacerbación de la realidad económica que se vivía: la concentración por la exclusión.

La nueva política urbana del Municipio giró en torno a tres aspectos interrelacionados: la «municipalización» del suelo urbano, el intento de control a la evolución «anárquica» de la ciudad y la inversión en ciertas obras de infraestructura9. Eso significa que la adquisición de los terrenos por parte de la municipalidad representó, paradójicamente, la consolidación de la fracción urbana terrateniente, y que lo fue en tanto permitió y posibilitó la transformación de la renta capitalizada (precio) — formada en el proceso de constitución y habilitación de la tierra y del suelo urbano (valorización) impulsada por el propio Municipio en los años anterioresen dinero y luego en capital, con lo cual se consolidó el propietario de la tierra en capitalista rentista bajo la sombra del cabildo de la ciudad.

Para tener una idea de la magnitud de la propiedad municipal de aquel entonces, leamos el informe presentado por el doctor Humberto Albornoz, presidente de la Comisión de Hacienda del Cabildo capitalino:

(...) por mi parte considero, y así propongo al Concejo, que la realización del Plan Regulador se inicie con la urbanización de los terrenos situados al Norte del Colegio Militar y de los cuales la Municipalidad es propietaria de 2’542.449 metros cuadrados, debiendo todavía expropiarse, para completar toda esa zona urbanizable, 1'133.100 metros cuadrados, pertenecientes a diversos particulares y que están junto a La Carolina, de propiedad del Municipio (...) (Municipio de Quito, 1949).

Si constatamos que estos terrenos se ubican exclusivamente en la zona norte de la ciudad y si comparamos estos datos con la superficie de Quito (1 200 ha) para aquella época (1949), veremos que el 30 \% del total del área urbana correspondía en propiedad al Municipio.

Esta política de tierra se complementó con los intentos de control del desarrollo futuro de la ciudad, bajo la regularización de los mercados de suelo urbano, la obligatoriedad de legalización de las urbanizaciones previa su venta y, principalmente, la formulación de un Plan Regulador de la ciudad. La expresión más acabada de esta lógica, se encuentra contenida en la propuesta del denominado «Plan Regulador de Quito», diseñado por el arquitecto uruguayo Jones Odriozola (1949)10. Aquel Plan asumió, en su contenido, la imagen de ciudad deseada por

años (1937-1939). La presentación de sus «curriculums» nos demuestra que todas nacen bajo la promoción estatal, sea a partir de contratos ofertados por el Gobierno nacional (carreteras, vía férrea, edificios públicos, etc.) sea por el municipio capitalino (pavimentación, obras de urbanización, servicios públicos, ornamentación, etc.) y, finalmente por las Cajas de Previsión Social (viviendas principalmente).

9 Desde 1922, año del centenario de la batalla de Pichincha, es altamente significativo el desarrollo del alcantarillado, pavimentación, energía eléctrica y de construcción de obras de educación, culturales, administrativas, etc. (ibídem), pero es un desarrollo altamente excluyente, que sigue y consolida a la segregación urbana.

10 La planificación de la ciudad se inicia en 1939 con la presentación del Plan propuesto por el Ingeniero Eduardo Pólit Moreno. Sin embargo, el análisis se concentrará en el propuesto por 
y para los terratenientes11, en un horizonte temporal señalado para el año 2000; pero que enfatizó al mismo tiempo, un «plan de mínima» para el corto plazo y para la regulación post factum de lo realizado sin «control alguno»12.

Será precisamente ese crecimiento «sin control alguno» el pretexto para «planificar» el desarrollo futuro de la ciudad, y también la posibilidad de que los terratenientes urbanos asuman una posición expresa. Se intentó crear una organización «controlada» que dirigiera el fraccionamiento y urbanización, y disminuyera la especulación indiscriminada de tierra13. Con esta perspectiva se dirigió el crecimiento urbano hacia el norte y se instauró el modelo jerárquico y segregado de «desarrollo urbano».

La racionalidad del plan no fue otra que la implementación de la lógica económica capitalista, señalada anteriormente; concentradora, en tanto que: 1) ecológicamente ubicó las funciones y usos urbanos principales en ámbitos territoriales específicos14; 2) densificó — por tugurización — el centro de la ciudad; y 3) permitió la acumulación capitalista de la renta del suelo en la fracción urbana de los terratenientes. Y excluyente, en cuanto adoptó como norma de planificación y acción a la segregación (residencial 15 y por usos de suelo), y marginó a la mayoría de la población de los más elementales servicios y equipamientos colectivos.

No se puede desconocer en este proceso, la importancia de la crisis de las exportaciones tradicionales, la depresión económica y guerra mundial, hechos históricos acaecidos durante el período y en su tiempo, que influyeron

el arquitecto Odriozola en 1942, por considerarlo la expresión más acabada de los intereses hegemónicos del momento.

11 La ideología terrateniente tiene su mejor propuesta en la formulación de la «ciudad jardín» en la zona norte (su zona), que no es otra cosa que la prolongación de la casa de hacienda a la ciudad, con su huerta y todo.

12 «Los propietarios de los terrenos trazaron calles, parcelaron y vendieron lotes con grandes ganancias sin ningún plan. Al Concejo le tocó la tarea de pavimentar esas calles, poner aceras, canalizar y dotar de luz, agua, etc., es decir, de urbanizar lo que la iniciativa privada guiada por el negocio había querido transformar en la ciudad. Esta ganancia debía venir de algún esfuerzo del propietario y no esperar que la ciudad crezca para sacar ganancia y luego utilizar al Municipio para que termine la obra que debe ser para todos y no sólo para estos propietarios». Informe del Alcalde Carlos Andrade Marín, presentado en 1940 (Achig, 1983: 55).

13 «Los auges de las lotizaciones corresponden más o menos ajustadas con las épocas a la divulgación del Plan Jones en 1945. Sólo en el papel ya tuvo la virtud de valorizar zonas que parecían tener futuro. Otro auge inmediato, lo marca el inicio de las lotizaciones comerciales hacia 1952. Y el mayor de todos hacia 1963, con la aparición de las mutualistas, cooperativas y las instituciones nacionales de vivienda, Banco, Instituto, etc.» (Banderas, 1967: 22).

14 La propuesta contempla por un lado, el desarrollo concéntrico o nucleado de funciones: centro cívico, centro deportivo, centro cultural, etc.; y, por otro lado, la especialización del territorio por usos y zonas demarcadas: zonas de vivienda (obrera, media, residencial), zonas de trabajo (industria, artesanado, oficinas y negocios), y zonas de esparcimiento (deportes, paseo y descanso). Todo ello distribuido y clasificado según el sur, el centro y el norte, e integrado por un sistema vial que refuerza e induce el esquema: no otra cosa son el conjunto de diagonales que se establecen (muy a lo Haussman en París) tanto en el norte como en el sur y hacia el centro.

15 Por primera vez el Municipio establece una política de segregación que adquiere mayor relevancia al momento en que se establecen categorías de barrios según su localización. Así tenemos, urbanizaciones de primera, segunda y tercera clase. 
notablemente en el comportamiento de la política urbana y en la evolución de la organización territorial, y de sus mecanismos intervinientes.

Del anterior carácter lineal, extensivo (costoso, anti-técnico, etc.), se pasó a una configuración longitudinal-polinuclear, relativamente conforme a la propuesta en el Plan y absolutamente adecuada a su espíritu general (fig. 3). Esa forma de organización territorial se presentó en realidad como una prolongación de la anterior más que como una enteramente nueva: no representa una ruptura con la preexistente, sino más bien, un nivel más elevado de su propia evolución.

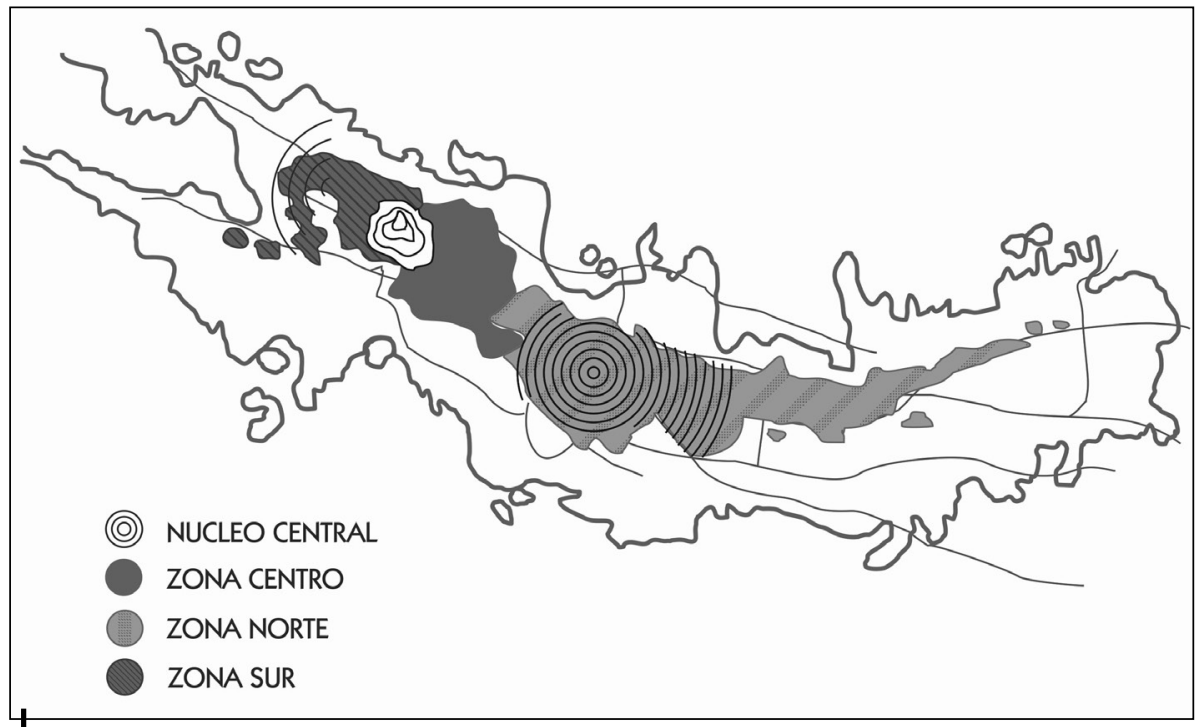

Figura 3 - Esquema de la forma de organización territorial longitudinal polinuclear $(\mathbf{1 9 6 0} \cdot \mathbf{1 9 7 0})$

Elaboración propia

Este proceso se basó en el hecho de que las tres zonas ecológicamente diferenciadas (norte, centro y sur), tendieron a ser modificadas al interior de cada una de ellas por la emergencia de polos o núcleos de articulación zonal (que dieron origen a centralidades urbanas); esto es, la conformación de áreas especializadas de actividad urbana (polos, núcleos, centros) que cuenten con ámbitos específicos de influencia (zonas) y que se encuentren mutuamente relacionados. Tal situación resultó de la especialización del territorio. En última instancia expresó un nuevo tipo de segregación urbana, construida a partir de la articulación de la tradicional segregación residencial con la segregación por usos de suelo que se incorporó de manera evidente en esa etapa. Su resultado concreto sería la consolidación de las zonas ecológicamente dispares: norte, sur y centro, y también la formación de gérmenes de centralidad en sus respectivos interiores: al norte la Mariscal Sucre, al sur la Villa Flora y al centro el «centro urbano».

Esta configuración se consolidó en un momento de crecimiento económico (fines del boom bananero) y de relativa estabilidad política en el país, y apareció 
como resultante de todo el período de transición urbana. Sin duda dos fueron los agentes principales en el período: el Municipio de Quito y los terratenientes de base urbana. En ese sentido, el Municipio asumió el papel de garante, promotor y legitimador de los intereses de la fracción urbana de los terratenientes, nacida y consolidada en el período. $Y$ lo hizo en tanto que sus acciones tuvieron una lógica evidente: promover un desarrollo urbano concentrado (polos) y excluyente (segregación), mediante la expansión, tugurización, vialidad y servicios emprendidos, lo que mostró la concordancia existente entre el municipio y su política, y los terratenientes y sus intereses.

\section{LA CRISIS URBANA CON LA MODERNIZACIÓN CAPITALISTA (1960-1990)}

La dinamización de la economía nacional a partir de la reactivación del modelo de agro-exportación (sobre la base de otro producto agrícola, el banano) determinó una integración mayor del país al concierto internacional, pero no solo eso: por las características que imprimió la plantación y la (re)estructuración del modelo de agro-exportación, la urbanización se aceleró significativamente a partir de los años 1960.

Quito y Guayaquil presentaron un acelerado crecimiento poblacional, paralelo al crecimiento urbano global del país; las ciudades intermedias de la costa adquirieron un alto dinamismo mientras que las de la sierra sufrieron un estancamiento relativo.

El proceso de urbanización se profundizó con la crisis del modelo de agroexportación y el resquebrajamiento del rol que cumplió el Ecuador en la división internacional del trabajo como productor de «bienes de sobremesa», con base al monocultivo de exportación. De allí que la forma bicefálica del proceso de urbanización (Quito-Guayaquil) se dinamizó: para la década de los años 1960 se intentó articular un modelo «desarrollista» que propugnó como eje matriz de la sociedad nacional a la industrialización sustitutiva de importaciones, y para los años 197016, su puesta en práctica bajo el influjo de los ingresos derivados de la producción y comercialización petrolera.

Estuvimos, entonces, en presencia del proceso de transformación de las formas de acumulación semi-coloniales o primario-exportadoras a las de sustento urbanoindustrial (Quijano, 1974: 82), teniendo como eje principal el hecho de que la plusvalía extraída en el sector minero y agrícola, que en períodos anteriores fluía directamente hacia los países industrializados, comenzó a ser acumulada localmente a través del desarrollo —aunque incipiente aún- de la industria, el comercio y la banca de base urbana y concentrada principalmente en Quito y Guayaquil.

16 Bajo esta perspectiva se movilizan cuantiosos recursos, nacionales e internacionales, hacia la industria, paralelamente a la formulación de una estrategia política que contempla la Reforma Agraria, Tributaria, Ley de Fomento Industrial, etc., inscritas en los postulados de la Alianza para el Progreso y ejecutadas por la Junta Militar de aquel entonces. 
Dentro de ese contexto nacional, las relaciones urbano-rurales y en general la estructura territorial de la producción, tendieron a readecuarse en función de los nuevos requerimientos económicos imperantes; la organización agro-exportadora que caracterizaba a la estructura territorial de la producción comenzó a sufrir sustanciales modificaciones, en el sentido de que las grandes ciudades (QuitoGuayaquil) se convirtieron en los centros articuladores de los circuitos internos de acumulación, del proceso de urbanización y de sus nuevas formas.

En suma: con el proceso de modernización capitalista vigorizado por el incremento de los recursos económicos provenientes de la exportación petrolera, se inició la redefinición de la concentración bicefálica de la urbanización nacional y consecuentemente del papel de Quito. De allí que la ciudad se convirtió en el centro de mayor dinamismo relativo del país, por cuanto la gran captación de los excedentes derivados de las regalías petroleras fueron manejados por el Estado, cuya cabeza más visible, la administración pública, tuvo por asiento a la capital de la república.

En este proceso de modernización capitalista del país, Quito comenzó a dar muestras, como organización territorial, de un relativo estancamiento primero y de un acelerado cambio después; es decir de crisis y transición urbana. Crisis que se expresó por ejemplo en el freno de la circulación de bienes y personas por parte de una organización territorial obsoleta; en la obsolescencia de las estructuras que se veían en el centro de la ciudad (crisis de centralidad urbana); en las modalidades de la propiedad urbana como límite relativo al desarrollo de la industria de la construcción, en la reproducción de la fuerza de trabajo, en la localización de las actividades urbanas principales, etc. Lo cual, en última instancia nos reveló el agotamiento de la forma polinuclear de organización territorial y de los mecanismos sociales de segregación que la prefiguran.

Las transformaciones de Quito (como organización urbano-territorial) no se hicieron esperar: entre 1962 y 1980 el área urbana tuvo un crecimiento cercano al 500 \%, y en ella no se consideraron las áreas conurbanas ni el crecimiento en altura; la densidad global de la ciudad bajó ostensiblemente de 213 a 68 habitantes por hectárea; aparecieron nuevas alternativas residenciales para los sectores de bajos ingresos en los eufemísticamente considerados «barrios periféricos»; se produjo una relocalización de las actividades industriales, comerciales y administrativas; el parque automotor de la ciudad creció en más de seis veces, etc. A la par del conjunto de la ciudad, se modifica el uso del suelo.

La salida capitalista a esta crisis urbana empezó a tomar forma a través de los siguientes componentes principales: el desarrollo de una nueva forma de organización urbano-territorial cualitativamente diferente a la anterior; el proceso de eliminación relativa de las restricciones que imponía la propiedad del suelo a la industria de la construcción; la consolidación de la fracción del capital especializada en la construcción y la promoción; y la adopción de una política urbana acorde a estas exigencias y expresiones.

Los procesos articulados de expansión y renovación urbana permitieron redefinir la forma metropolitana de organización urbano-territorial (fig. 4), debido a que 
la lógica de constitución, habilitación e utilización del suelo urbano se conformó territorialmente desde la segregación y la relación centro/periferia.

Esta relación se erigió como dominante por el alto dinamismo que se observó en las fuerzas productivas en el país desde la década de 1960 - y con mayor énfasis desde la comercialización petrolera (1972) — cuya influencia se hizo notoria en el desarrollo de la división social y técnica del trabajo y en las comunicaciones en general (medios de comunicación, información y transportación), al punto que tendieron a reducir el obstáculo que significó el territorio (esta vez como distancia y no como elemento de la producción) para el capital, mediante los procesos interrelacionados de integración de nuevos ámbitos territoriales (conurbación) y de dispersión de ciertas funciones principales (la industria).

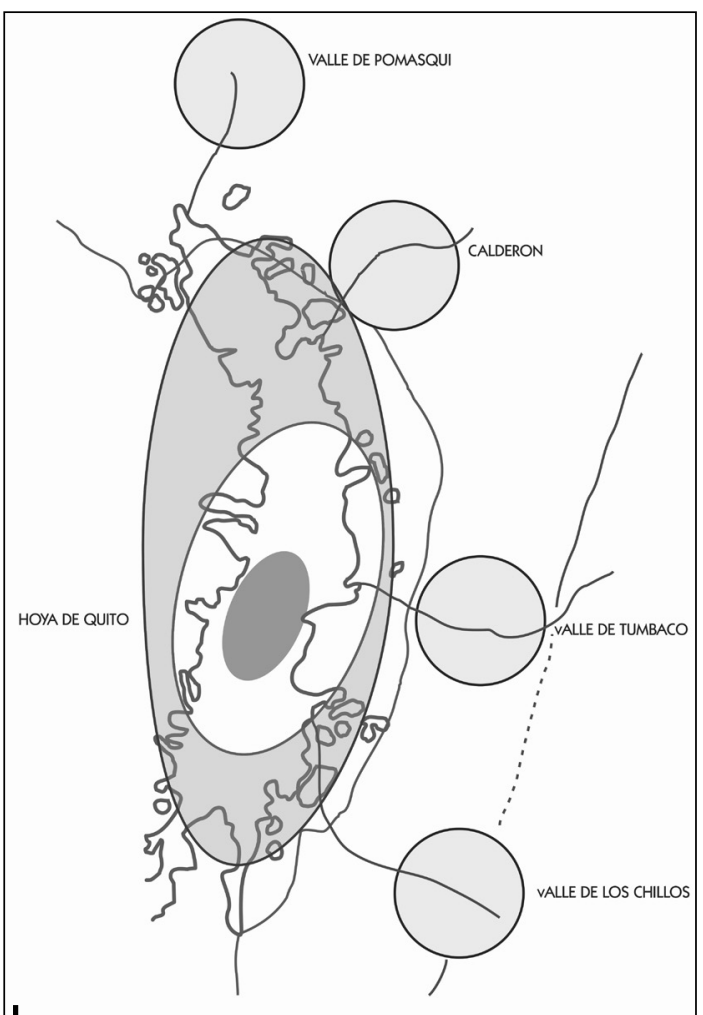

Figura 4 - Esquema de la forma de organización territorial de área metropolitana

Elaboración propia

De allí por ejemplo, el rol que juega la urbanización de los valles circundantes a la ciudad, la relocalización de ciertas funciones urbanas (industria, administración, etc.), en unos casos a la manera de callejones que siguen la dirección de las carreteras y autopistas, construidas en la última década y basadas en poblados anteriores pero hoy transformadas y conurbadas, y en otros casos más con la formación de nuevas unidades. Sin duda uno de los aspectos más sobresalientes estribó en el hecho de que se empezó a generalizar una nueva forma de implantación industrial —al menos para aquellas fábricas que contaban con alta composición orgánica de capital - en la periferia de la ciudad; con la característica adicional de que sus mecanismos administrativos se ubicaron en el centro metropolitano. Es decir, que esta división técnica del trabajo al interior de una misma unidad de producción asumió una expresión urbano-territorial absolutamente nueva, que condujo a la metropolización de la economía urbana.

No es casual entonces, que en estos últimos tiempos estemos presenciando con mayor nitidez la variación cualitativa de la forma de organización urbano-territorial y sus nuevos mecanismos. Si en las etapas anteriores su expresión era exclusivamente en términos longitudinales nortecentro-sur, hoy, a más de ella, y como prolongación cualitativamente diferente, se tiene una segregación que va del núcleo central hacia las zonas más apartadas. Una segregación que tiende a parecerse a la existente en la mayoría de las ciudades 
latinoamericanas, en el sentido de que en la actualidad se cuenta con barrios populares en precarias condiciones de existencia a lo largo de toda la superficie de la ciudad. O sea que las favelas, villas miserias, pueblos jóvenes, suburbios, etc. (nombres dados a la problemática en otras ciudades) se han convertido en realidad, con lo cual Quito ha dejado de ser la excepción y ha entrado en la norma de la ciudad latinoamericana.

Obviamente que estos cambios no pueden explicarse sin al menos la mención del desarrollo capitalista que se tuvo en el país en las últimas décadas: el desarrollo industrial, el crecimiento y modernización del Estado, el nacimiento de la industria de la construcción, la expansión de la inversión extranjera, entre otros. En este marco general se observa otro hecho de profundo contenido urbano: el aparecimiento del promotor inmobiliario y de la industria de la construcción (mercado al centro), apadrinado por el Estado a través de sus distintos órganos. Su nacimiento se remonta a los primeros años de la década del sesenta, en el marco político-económico de la Alianza para el Progreso, cuando fluyen ingentes cantidades de capitales norteamericanos para el financiamiento del mutualismo, la banca privada y ciertos organismos estatales comprometidos con la construcción de viviendas. El Municipio juega un papel fundamental adicional: su función es la de eliminar obstáculos que significa la propiedad de la tierra para la acumulación de capital; con lo cual se evidencia un nuevo carácter que asume la política urbana municipal. Esto es la puesta en marcha de una política urbana concertada bajo la hegemonía del capital de promoción, que tiende a consolidar la segregación urbana (como forma de organización urbano-territorial) vía la transición (expansión y renovación urbana, y el gasto público).

Por el carácter de la transición y por la modalidad concertada de la política urbana, la lógica de readecuación de la ciudad — vía expansión y renovaciónes lenta, paulatina y progresiva; de alguna manera sigue el ritmo que impone la formación y desarrollo de las fuerzas sociales involucradas (una de las cuales es el Estado) y de la política de acuerdos y concertación a que se llegue entre ellas. Bajo este contexto ocurre el crecimiento y transformación de la ciudad (expansión de la centralidad y desarrollo de la periferia), con la influencia de los cambios de centralización, concentración y relaciones centro-periferia.

\section{CONTEXTOS ACTUALES: RENOVACIÓN Y EXPANSIÓN URBANA EN EL SIGLO XXI}

El actual proceso de transformación urbana, por renovación y expansión urbana, se originó históricamente en la dinámica de la década de los años 1960 y se consolidó en el marco de la coyuntura petrolera, cuando el Estado y las fuerzas sociales involucradas adquirieron un elevado nivel económico, lo que posibilitó, sobre todo al Municipio, desarrollar instrumentos fundamentales de políticas de suelo, vialidad, servicios, equipamiento, etc. En estos momentos, se empieza a evidenciar el fenómeno de desarrollo conjunto, de alguna manera inédito en Quito, de la centralidad y la periferia. 
Sin duda el desarrollo de los medios de comunicación y de las fuerzas productivas en general han permitido redefinir la relación centro-periferia; eso, por un lado, posibilita reducir la fricción que impone el territorio para la complementariedad de las actividades socioeconómicas y, por otro lado, permite una mayor división y cooperación del trabajo. De allí se deriva la necesidad de la renovación y la expansión urbanas, considerando, además, que el proceso urbano global comienza a generar desaceleraciones económicas, a evidenciar la caducidad del crecimiento lineal, a producir escasez de tierra, a influir en el medio ambiente, etc.

El desarrollo vial y de las comunicaciones en general es parte y resultado de la constitución, habilitación y apropiación del territorio urbano, tanto en la periferia como en el centro de la ciudad. En esa perspectiva se explica el desarrollo de los «valles» (Pomasqui, Tumbaco, Los Chillos, etc.), de los «anillos periféricos» (integrador de los valles y de circunvalación de la ciudad), de los «ejes viales» (longitudinales y transversales) de las «facilidades de tránsito» (túneles, pasos a nivel, etc.), y del equipamiento (terminal terrestre, parqueaderos, etc.).

En definitiva, se puede decir que el impulso tanto a los procesos de renovación como de expansión urbana estuvo dirigido, entre otros aspectos, a salvar el escollo que significa la escasez relativa de suelo para la construcción, la industria, la vivienda, etc. Ello se lo consigue mediante el inicio de un proceso de producción (habilitación) del suelo urbano a través de la concentración de la propiedad y de su fraccionamiento (caso de la expansión urbana). Estos procesos los desarrolla el Municipio a través de una serie de acciones de orden legal, político, económico, ideológico y, hasta, represivo; acciones que, debido a su magnitud, a la desvalorización del capital invertido, a la baja rotación de capital, a la poca rentabilidad directa de beneficio capitalista, no son asumidas por el capital privado que, en cambio, sí se apropia de sus beneficios (los conjuntos cerrados)17.

El impulso a los procesos de renovación y expansión urbana significa también, en la práctica, una forma de «gestión del déficit» en el conjunto de la ciudad. No otra es la política del Municipio en la actualidad, en cuanto que la «gestión del déficit» se encuentra enmarcada bajo una lógica empresarial del manejo del Municipio y de la consecuente marginación de amplios sectores de la población urbana de los servicios y equipamientos colectivos fundamentales. Lo uno es resultado de lo otro: no es rentable empresarialmente el dotar de agua potable, alcantarillado, energía eléctrica, teléfonos, transporte, etc., por ejemplo, a los llamados «barrios periféricos». De allí se puede colegir, que es preferible, para esta lógica empresarial del Municipio, expulsar un grueso porcentaje de población residente en las zonas centrales de la ciudad, hacia el margen exterior del perímetro urbano establecido por el Municipio - lo cual obviamente implica considerar a esta población al margen de los servicios y equipamientos colectivos-, que el mantenerla al interior de la ciudad considerada legal y dotar, a «pérdida», los servicios. Así, en los últimos 18 años el Centro Histórico de Quito perdió el 41 \% de la población residente.

17 Adicionalmente el capital comprometido en la rama de la construcción obtiene otro beneficio: ganancia superior a la media extraída de las etapas más rentables del conjunto del ciclo productivo emprendido por el Municipio. 
El expulsarlos de las zonas centrales hacia las afueras de la ciudad implicó, al menos las siguientes situaciones: primero, en las zonas de renovación urbana, el poder intensificar el uso de la tierra con otras fuentes más rentables para el capital y los terratenientes; segundo, en las zonas de expansión, poder desarrollar un mercado de la tierra con características especulativas (rentas de monopolio principalmente) que benefician a los terratenientes, intermediarios, promotores inmobiliarios, etc., en detrimento de la población allí residente; tercero, en relación con los servicios y equipamientos colectivos propiamente dichos, poder entrar en un proceso de negociación de tipo clientelar de dominación hacia estos sectores mayoritarios

\section{CONCLUSIONES}

Más que conclusiones, se trata de ideas centrales de este proceso investigativo, o más concretamente, hipótesis con las cuales se estudia el desarrollo urbano de Quito. Por ello, lo que presentamos son puntos de partida que merecen ser resaltados:

- El desarrollo urbano de Quito presentó tres períodos claramente identificados: el primero que va desde la Revolución Liberal hasta fines de la década de 1950, el segundo hasta fines del siglo pasado y el último que llega hasta la primera década del siglo actual. El origen de cada período lo definimos como «crisis urbana» y su desarrollo como de transición-estabilización. En suma, Quito, es un proceso cíclico de evolución, que estaría en consonancia con los cambios provocados en la articulación de las relaciones de producción y la socialización de las fuerzas productivas.

- La forma de organización territorial evoluciona de manera indirecta (por oposición a casualidad lineal) frente a la sociedad. De allí que las formas radialconcéntrica, longitudinal (polinuclear) y metropolitana reflejan la particular distribución que adoptan los valores de uso autónomos en el valor de uso complejo (la ciudad), en cada uno de sus períodos.

- La función que ejerce el Municipio está determinada en la articulación de la sociedad civil y el Estado en cada coyuntura específica. De allí se deduce que el Municipio sea un órgano estatal con poder real pero limitado. Sin embargo, debe señalarse que la política urbana del Municipio siempre privilegió al suelo urbano, pero asignándole, según el momento, funciones diferentes. Así tendremos al principio (hasta 1933) una política de valorización (producción) de la tierra urbana y otra de monetarización de la renta capitalizada (fines de los años 1970); hacia la década de 1960 más bien de liberación del obstáculo que significa la propiedad de la tierra para el capital inmobiliario. Esta caracterización no niega la coexistencia simultánea de ello; lo que hace es resolver el predominio que ejerce una sobre las restantes.

- En consideración a las funciones que desempeñan la política urbana del Municipio, puede concluirse que sus principales beneficiarios han sido en su orden (y simultáneamente) los terratenientes urbanos, el capital inmobiliario 
y el capital financiero internacional. De allí la definición de política urbana concertada, por cuanto se produce una «alianza de intereses» en el Municipio, pero siempre, según el momento, bajo la égida de uno de ellos.

- El patrón de urbanización de la ciudad expansivo y centrífugo, se sustentó en la dispersión de los asentamientos populares en la periferia, apoyada en dos formas de irregularidad: la localización y la ocupación de la población en terrenos invadidos y el irrespeto a las normas urbanísticas venidas de los planes reguladores urbanos. Esta doble irregularidad se tradujo en la ausencia de inversión pública en estos barrios y en el punto de partida para la estigmatización la barriada popular.

- Las infraestructuras principales estaban destinadas a los asentamientos humanos de la periferia y a buscar los mecanismos de integración a la ciudad central; esto es, a la habilitación de suelo urbano para la localización de población. Sin embargo, por el tamaño de la demanda y su carácter ilegal, fue muy difícil solventar estas infraestructuras, lo cual condujo a mecanismos informales o ilegales, que reprodujeron la problemática. En energía eléctrica («tallarines») los incendios frecuentes, en agua potable (tanqueros) la salubridad, en evacuación de desechos (cielo abierto) la contaminación. Estos asentamientos humanos no produjeron ciudad y los servicios fueron más costosos y de inferior calidad a los producidos formalmente; por lo cual la ciudad formal perdía y la informal también. Las ciudades de pobres son pobres y los pobres de las ciudades pagan mucho más y reciben servicios de menor calidad que los habitantes formales de la ciudad. La pobreza resultó ser muy cara, en todo sentido.

- En la actualidad estas demandas de necesidades básicas se cierran y simultáneamente se abren otras, propias de la ciudad relacional: conectividad, cooperación-competitividad y posicionamiento. Este salto significa un cambio de la funcionalidad de las infraestructuras, un incremento del peso relativo de otras y también el aparecimiento de nuevas. En la ciudad relacional, las infraestructuras demandadas son distintas, porque las relaciones interurbanas son el elemento central de su desarrollo. Por eso los servicios urbanos vinculados a las nuevas tecnologías de las comunicaciones, como la telefonía, los puertos, los aeropuertos, el internet y las autopistas son esenciales; pero también lo son las infraestructuras ligadas a las finanzas (teletrabajo, Internet), a la producción (energía eléctrica, agua potable) y a la calidad de vida (seguridad, educación).

\section{Referencias citadas}

ACHIG, L., 1983 - El proceso urbano de Quito, 107 pp.; Quito: Ediciones Ciudad.

AYALA, E., 1982 - Lucha política y origen de los partidos políticos en el Ecuador, 371 pp.; Quito: Corporación Editora Nacional.

BANDERAS, D., 1967 - Informe sobre el fraccionamiento de la tierra en el área urbana de Quito. In: Plan Director de Urbanismo de San Francisco de Quito: 22; Quito: Editorial Municipal. 
CARRIÓN, F., 1979 - Crisis urbana y organización territorial en Quito, 255-267; Quito: Editorial Colegio de México.

CARRIÓN, F., 1984 - Las ciudades intermedias en el contexto de la urbanización ecuatoriana. Revista SIAP, 71 (1): 129-147.

CASTELLS, M., 1981 - Crisis urbana y cambio social, 332 pp.; México: Editorial Siglo XXI. MUNICIPIO DE QUITO, 1949 - Plan Regulador de Quito; Quito: Editorial municipal.

PAZ y MIÑO, L., 1960 - Cartografía quiteña, 28-34; México: Editorial Instituto Panamericano de Geografía e Historia.

QUIJANO, A., 1974 - Imperialismo y relaciones internacionales en América Latina. In: Relaciones políticas entre América Latina y Estados Unidos; Buenos Aires: Editorial AmorrutoEditores.

SALGADO, G., 1978 - Lo que fuimos y lo que somos, 41-74; Bogotá: Editorial Siglo XXI 